\title{
A Study on the Legal Issues of Music Copyright in Korea and Japan
}

\author{
Myeong Seob Lim \\ Graduate School of Global Cultural Contents, \\ Hankuk University of Foreign Studies, \\ 107 Imun-ro, Dongdaemun-gu, Seoul, Korea; \\ Kyoung Hee Kim \\ Graduate School of Global Cultural Contents, \\ Hankuk University of Foreign Studies, \\ 107 Imun-ro, Dongdaemun-gu, Seoul, Korea;
}

\begin{abstract}
Copyright is an essential right of the creator and an important element of the culture creation industry. However, it is a misconception that the copyrighted property is the property of the copyright owner and that the copyright law protects the rights of the copyright owner only. Because the ultimate goal of copyright is to improve and develop the cultural industry. For the development of the cultural industry, it is very important for the producers who make the contents or those who commercialize the contents to understand the copyright. In this study, we will propose a promotion method of the music industry by examining the problem by investigating cases of collection of copyright fees, collecting regulations, and related copyright laws of both Korea and Japan.
\end{abstract}

Keywords: Music Copyright laws, trust service, royalties collection rules, JASRAC, Korea, Japan

\section{INTRODUCTION}

The development of cultural industry has been leaded to the political development. A lot of regulations and policies have been developed and revised in regard to the cultural industry. Copyright, most of all, is the most important factor in cultural industry and is a just right that creators must have. Music copyright is a right where creators can allow or prohibit the use by music creations. Songwriters, lyricists, musicians and record producer can have this right. To protect the music copyright, government establishes and practices copyright law. In other words, copyright law aim to protect the right of creators and interested party and to develop cultural industry by promoting fair usage of contents. Copyright includes different rights according to the form of usage. The author is rewarded for his creation by allowing the use of the work and receiving the royalties he pays for it. In addition, Sports and Tourism, Ministry of Culture and Korea Copyright Commission explains the reason for the protection of copyright as in [1]

Copyright aims at ultimate development of Korea's culture related industry by providing contents creators motivations(incentives) to help them concentrate on the creation itself. This can be resulted in accumulation of world's human cultural heritage in the future. [1]

If so, can the protection of Copyright always evoke a promotion of cultural industry? Recently in Japan, there has been controversies surrounding collection of copyright royalty for Music 
Class. There have been two conflicted ideas between the organization where protects the Copyright thoroughly and the Music Education association that claims it as overpaid. The purpose of this research is to investigate the royalty collection cases, collection regulations and copyright laws related to Korea and Japan and to suggest measures for the promotion of music industry by examining problems on the copyright enforcement.

\section{FOR EFFECTIVE COPYRIGHT PROTECTION, TRUST SERVICE}

The Korean Copyright Act divides the copyright into the copyright law and the property rights of the author as Table 1. from 'Music industry white paper 2016'. And economic rights are the rights that the author must observe when the work is actually used.

\section{Table.1. classificatied Author's economic right}

\begin{tabular}{|c|l|}
\hline Right of reproduction & $\begin{array}{l}\text { To fix to or reproduce to a type by recording or other } \\
\text { method }\end{array}$ \\
\hline $\begin{array}{c}\text { Right of Public } \\
\text { Performance }\end{array}$ & $\begin{array}{l}\text { Performers shall have the right to perform his/her } \\
\text { performance publicly which has not been fixed }\end{array}$ \\
\hline $\begin{array}{c}\text { Right of Public } \\
\text { Transmission }\end{array}$ & $\begin{array}{l}\text { transmitting works, stage performances by making such } \\
\text { available to the public by wire or wireless means so that } \\
\text { the public may receive them or have access to them }\end{array}$ \\
\hline Right of Distribution & $\begin{array}{l}\text { The author shall have the right to distribute the original or } \\
\text { copy of his/her work }\end{array}$ \\
\hline Right of Rental & $\begin{array}{l}\text { Performers shall have the right to lend the commercial } \\
\text { phonogram, in which his/her performance is recorded, for } \\
\text { profit-making purpose }\end{array}$ \\
\hline $\begin{array}{c}\text { Right of Production of } \\
\text { Derivative Works }\end{array}$ & $\begin{array}{l}\text { Rights to create and use edited works whose A secondary } \\
\text { work that based on original work or part of original work }\end{array}$ \\
\hline
\end{tabular}

(Source: Music industry white paper 2016)

Music creators register for copyright to protect their creations. And register copyright to protect his rights. In fact, only the creation of a work can be protected by the Constitution and the Copyright Act. However, copyright registration can be notarized for its own work and creates legal effect. For example, if you do not register copyright, you must prove it all by yourself. However, if the copyright is registered, as Figure. 1. made by Korea Copyright Commission, the court can estimate and fight against it, and it is possible to easily protect the copyrighted works such as claims for damages and extension of the protection period.

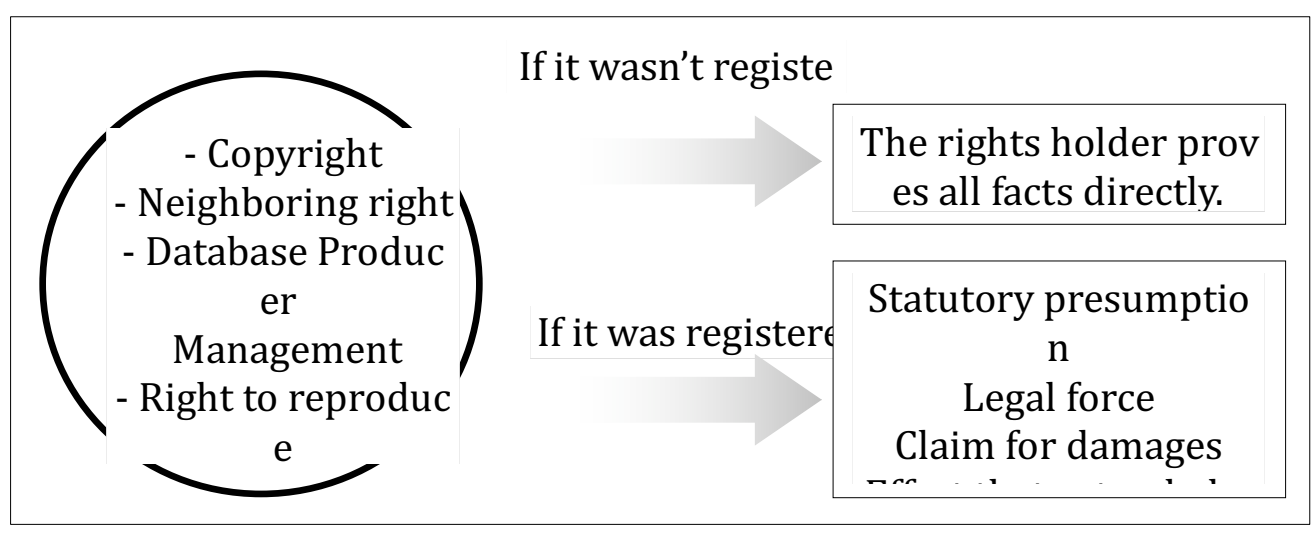

Fig.1. The effect of copyright registration

However, in reality, it is necessary to consider trust service for music creators to exercise their rights. Compared to other genres, it is easier to keep in touch with related contents due to the attributes of music. It is impossible to monitor all the situation about how and where the music that creator has created is utilized. Therefore, creators cannot exercise music copyrights by 
their own efforts. That's why it is important to find a copyright specialized organization where can manage copyright on behalf of creators.

Current Korea Copyright Law Article 2, 26 as follows [2]

The term "copyright trust service" means a business which continuously manages rights on behalf of the holder of economic rights of author, an exclusive publication right, publication right, or neighboring right or a person who has the right as a database producer, and which includes the case of a general agent regarding exploitation of works [2]

As indicated, it describes Copyright management business as a business that mediate or subrogate the right for contents creators and neighboring right. As of 2018, there are 4 trust service organizations: Korea Music Copyright Association (KOMCA), Federation of Korean Music Performers, Recording Industry Association of Korea, The Korean Society of Composers, Authors and Publishers. Music Copyright specialized organizations, compared to other cultural industry organizations, have large occupied portion of royalty costs in Accounting. This shows the necessity of trust service especially for music Copyright compared to other genres.

This leads to another topic about how trust service organizations manage and protect the right of contents creators. Copyright trust service organizations protect the right of music creators under Copyright law and manage every licenses and its rights on behalf of the creators. Every work from trust service organization aims at the contribution to the development of music culture industry. Music creators entrust their rights by paying a certain amount of commission to professional management organization for clear and convenient compensation for creations. Management organizations are provided the right from creators and as a compensation they collect commission. Also, they make a deduction from some amount of commission and distribute it to creators. In this way, contents creators, copyright trust service organizations and Copyright Law are closely related to one another. In real situation, however, conflicts can be evoked as the result of opinion differences about royalty collection regulations.

\section{CONFLICTS BETWEEN JASRAC AND MUSIC EDUCATION INDUSTRY}

Copyright is created automatically when a work is created. It is the outcome of original creation and uniqueness. In Copyright Law of Japan Article 2. 1 as [3], the following definition of works is defined.

production in which thoughts or sentiments are expressed in a creative way and which falls within the literary, scientific, artistic or musical domain. [3]

It is a work that creatively expresses author's intention in each field, and it should be protected. JASRAC is working on the economic rights of authors. JASRAC (Japanese Society for Rights of Authors, Composers and publishers) is a representative copyright trust service organization in Japan music industry. JASRAC is in charge of an overall management about copyright and is considered as the most influential organization in Japan since the establishment in 1939. JASRAC is operated by general corporation law and have a purpose to popularize the idea of copyright and to develop music culture. JASRAC's efforts to protect copyright can be found in royalty collection regulation policy. As Figure 2, it is necessary to provide JASRAC authorized number in Japanese publications or comic books where include JASRAC registered lyrics. In addition, JASRAC is doing thorough management by requesting to delete uploaded videos on foreign video website that violate copyright laws. 


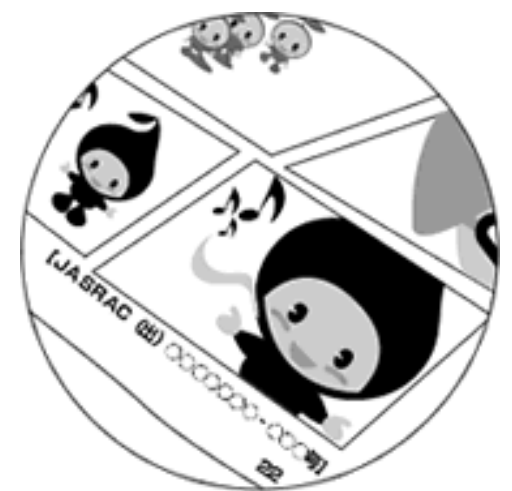

Fig. 2. JASRAC number when posting lyrics in cartoon

This is the responsibility and duty at the same time for the organization, JASRAC must have. Since JASRAC is entrusted rights from the original creators, it is important to put best efforts to protect their rights and compensation. However, these activities have been controversial in music market. JASRAC started to gradually expand royalty collection targets according to performance rights of music organizations since 2003; Physical Education facilities in 2011, cultural center in 2012, dance academies in 2015 and singing classes starting from 2016. In February 2017, JASRAC announced to collect royalty from music classes starting from 2018 . As a reaction to this, music education organizations centering on 'YAMAHA Music Class' created 'protecting music education organization' and started to spreading opposition movement from the royalty collection. They claim that it is not appropriate to collect royalty from music usage in music classes not in recital or performance. However, according to the current Law, JASRAC's claim is not considered as illegal. Composition is also a creation so it needs creator' $s$ permission to play or duplicate the song. If the creator chose trust service like JASRAC to protect his/her right, JASRAC can provide or prohibit the access about the song. However, it is stated like followings in Japan copyright law Article 22 [4]:

The author shall have the exclusive right to perform his work publicly ("publicly" means for the purpose of making a work seen or heard directly by the public; the same shall apply hereinafter) [4]

That is, a performance right is defined as a playing right that aims at the purpose of making a work heard directly by the public. On the other hand, 'protecting music education organization' claims that it is not considered as a copyright law Article 22 because the playing in music classes is not for listening but for teaching or practicing. There can be an opposing opinion on this idea. In the statement 'Aim at showing or listening in the air', playing is an object of playing rights. This means that students' piano playing practices are not this case.

However, the cases where a teacher shows how to play or where listening to CD on sale are considered as this case. So it is hard to declare that JASRAC's grounds are fully away from the definition of playing. There are worries that JASRAC's policies that originally aim at the development of music culture can inversely lead to change the flow of creation usage and can negatively affect to the development of music culture. As stated above, JASRAC's first priority is to protect copyright and through this JASRAC claims that they can actualize the sustainable development of culture.

Although there has been a consistent conflict, JASRAC announced that they will collect $2.5 \%$ of tuition as a fee starting from January 2018. Also JASRAC considers music classes as collection target and demands them to make contracts. As the reaction to this, in June 2017 'protecting music education organizations' sued against JASRAC to make it clear that JASRAC has no right for fee collect and the organization currently request Agency for Cultural Affairs to reorganize 
collection regulations. Meanwhile, JASRAC sees music education as one of its revenue-making businesses and sticks to its policy to collect royalties for music copyright.

However, it is hard to interpret copyright law Article 1's "development of culture" as it only applies composers and lyricists who make music. That is, if music users are excluded from copyright law, it could be shown as a mistaken legalistic judgement. Prof. Nakayama(2017), a member of culture commission and an expert in intellectual property law, drew up an written opinion on 'protecting music education organizations'. Nakayama argued on playing right that JASRAC is claiming as follows [5]

Intangible use rights of the work that Include a performance It needs to be used for the general public as well as for mere use (Japan Copyright Law Article 22). In the case of copying, there is a risk that the copy will leak out as the number of copies increases. Therefore, although the reproduction itself is prohibited. but the performance is intangible reproduction, so even if it is used, it disappears, and since there is no possibility of a third party, only the performance performed for the public is prohibited. [5]

Prof. Nakayama claims that music institute performances are not subject to copyright law. and refute the problem raised by JASRAC through specific cases.[6]

For a music class in question, there can be no other than the students and teachers (or employers) who will be the performers. If the student is a performer, the prospect is a teacher. In this case, the audience corresponds to a certain minority. It is not the general public. When interpreting the concept of the public, it should be determined on the basis of social inequality, harm or civic emotion, which must take into account the actual state of the music class. [6]

He points out that JASRAC's interpretation of copyright law is sectional. As can be seen in the case of Japan, the interpretation of the Copyright Act can be problematic even among related parties. because, The misinterpretation of the law can have a negative impact on the development of the music industry.

\section{KOREAN MUSIC COPYRIGHT ISSUE}

Established in 1964, the Korea Music Copyright Association (KOMCA) is responsible for the trust service of copyrighted works of musical works. Recently, in the Korean music copyright industry, disputes about collection regulations between trust organizations and business places are appearing. In 2017, the Ministry of Culture, Sports and Tourism passed the revision to the Enforcement Decree of the Copyright Act at a Cabinet meeting. According to a press release by the Culture, Sports and Tourism Ministry, it has decided to establish a new rule to collect royalties from the place of high importance for music.

In addition, supplementary measures were taken to minimize the burden of users paying royalties in consultation with the music industry. Recently, however, KOMCA has been overestimating the amount of money that has been negotiated to cause disputes with the selfemployed people. 
Table. 2. Revised the rules for charge collection of Coffee shop, Non-alchol drink bar, Beer pub, Other Bar business.

\begin{tabular}{|c|c|c|}
\hline Grade & Area that permited Business & Flat rate (1month) \\
\hline 1 & Less than $50 \mathrm{~m}^{2}$ & 10,000 \\
\hline 2 & $50 \mathrm{~m}^{2} \sim 100 \mathrm{~m}^{2}$ & 20,000 \\
\hline 3 & $100 \mathrm{~m}^{2} \sim 200 \mathrm{~m}^{2}$ & 30,000 \\
\hline 4 & $200 \mathrm{~m}^{2} \sim 300 \mathrm{~m}^{2}$ & 45,000 \\
\hline 5 & $300 \mathrm{~m}^{2} \sim 500 \mathrm{~m}^{2}$ & 60,000 \\
\hline 6 & $500 \mathrm{~m}^{2} \sim 1,000 \mathrm{~m}^{2}$ & 75,000 \\
\hline 7 & $1,000 \mathrm{~m}^{2}$ and over & 90,000 \\
\hline
\end{tabular}

Table. 3. Revised the rules for charge collection of fitness center.

\begin{tabular}{|c|c|c|}
\hline Grade & Area that permited Business & Flat rate (1month) \\
\hline 1 & Less than $50 \mathrm{~m}^{2}$ & 12,000 \\
\hline 2 & $50 \mathrm{~m}^{2} \sim 100 \mathrm{~m}^{2}$ & 26,000 \\
\hline 3 & $100 \mathrm{~m}^{2} \sim 200 \mathrm{~m}^{2}$ & 45,000 \\
\hline 4 & $200 \mathrm{~m}^{2} \sim 300 \mathrm{~m}^{2}$ & 65,000 \\
\hline 5 & $300 \mathrm{~m}^{2} \sim 500 \mathrm{~m}^{2}$ & 86,000 \\
\hline 6 & $500 \mathrm{~m}^{2} \sim 1,000 \mathrm{~m}^{2}$ & 120,000 \\
\hline 7 & $1,000 \mathrm{~m}^{2}$ and over & 160,000 \\
\hline
\end{tabular}

As it is a new regulation, it is not a decided revision yet. However, the revision is very different from the agreed amount. It follows the ultimate goals of JASRAC and the KOMCA. Both organizations protect the author and ensure that the copyright is exercised properly. They collect as much royalties as possible and distribute them to members of the musical works they manage. Nor can we legally say that they are necessarily wrong. But, Acts that are faithful to copyright law can make the relationship with music users rather uncomfortable. Korea's case is a social conflict arising in the process of complying with copyright laws. Unlike Japanese cases, the interpretation of legal provisions is not an issue.

However, it is common to consider differences in each position and draw up a consultation point for promoting the cultural industry. In particular, government agencies can mediate between industries and enact laws on current issues. Currently, copyright laws require legal judgment for mutually complementary policies rather than determining the importance of one side. Although it appears to be a monetary and monetary problem, it can be a measure to promote the cultural industry in the long run.

\section{CONCLUSIONS}

JASRAC and Korea Music Copyright Association, both organizations are the copyright management companies that represent each country. The case of JASRAC is a big suggestion in Korea. Although it is not a legal issue, it is a controversial issue in the Japanese music scene at present, and it may be a controversial issue in Korea. For the further development of cultural industry, it is important for content creators and businesses where utilize existing contents to have accurate understandings upon copyright. There is also controversy in the process of revising the collection of royalties for musical works in Korea. Regulation was proposed to extend the scope of the copyright application, but it is causing a conflict as it differs from the original agreement.

Policies should not end with legislation and regulations. Both sides should be understood and the measures should be taken in a convincing direction without being unfair. JASRAC and the 
Korean Music Copyright Association are both about protecting the rights of artists. Music users are also key to growing the market's pies. The current disputed copyright law requires a judicial judgment based on complementary policies, not on which side is more important.

\section{ACKNOWLEDGMENTS}

This work was supported by the Research Fund from Hankuk University of Foreign Studies.

\section{References}

Allen Bargfrede, Music Law in the Digital Age: Copyright Essentials for Today's Music Business, Berklee Press, Boston (2017).

Ha Dong Chul, in Music Copyright, CommunicationBooks, Seoul (2013).

Industry Promotion Policy Division, in 2016 Music industry white paper, 464-465, Korea Creative Contents Agency (2017).

Matsuzono Nobuo, in introduction of JASRAC, NIPPON HYORON SHA PUBLISHERS, Tokyo (2009).

Nakayama Nobuhiro, in Copyright Law, Yuhikaku PUBLISHING, Tokyo (2014).

Park Sung Ho, in Copyright Law, 334-341, Pakyoungsa, Seoul (2017).

Brian T.Yeh, Copyright Licensing in Music Distribution, Reproduction, and Public Performance, Congressional Research Service, Washington D.C. (2015).

Eika Yamaguchi, Recent Characteristics of Royalties and License Fees in Japan's Balance of Payments, Bank of Japan Working Paper Series, Bank of Japan, Tokyo (2004).

Hayashi Shuya, Wu Kunlin, Exclusionary Effects of Blanket Copyright Agreement Offered by a Dominant Firm - A Case Study on Abuse of Dominance in Japan and Its Justifications, Academic Society for Competition Law, Meiji University, Japan. (2015).

Kataoka Tomoyuki, Present of Music copyright management organization in Japan, Culture Media Entertainment Laws, Vol. 9(2), 23-44, The institute for Culture Media and Entertainment Laws, Seoul (2015).

Michael Schlesinger, The Right of Making Available and its Implementation in National Law and Case Law, Vol. 11, 188, Intellectual Property Law and Policy, OXFORD AND PORTLAND, OREGON (2010). 